\title{
THE PUZZLE OF IMAGINATIVE DESIRE
}

\author{
Amy Kind \\ akind@cmc.edu
}

Note: This is a preprint of an article whose final and definitive form will be published in the Australasian Journal of Philosophy in 2011. The Australasian Journal of Philosophy is available online at: http://www.tandf.co.uk/journals/.

\begin{abstract}
The puzzle of imaginative desire arises due to the difficulty of accounting for the surprising behaviour of desire in imaginative activities such as our engagement with fiction and our games of pretend. Several philosophers have recently attempted to solve this puzzle by introducing a class of novel mental states-what they call desire-like imaginings or i-desires. In this paper, I argue that we should reject the i-desire solution to the puzzle of imaginative desire. The introduction of i-desires is both ontologically profligate and unnecessary, and most importantly, fails to make sense of what we are doing in the imaginative contexts in question.
\end{abstract}

\section{Introduction}

It's no surprise that imagining and desiring are connected in all sorts of ways. Our desires often prompt imaginings. My desire for the Mets to avoid yet another September collapse, for example, might cause me to imagine Carlos Beltran hitting a grand slam in their final game of the season. Our imaginings also prompt desires. When thinking about where to go out for dinner this weekend, I might imagine the chocolate soufflé at my favorite restaurant, which in turn might prompt an intense desire for one. We can desire that we imagine something - in an effort to remember a lost loved one, I might want to imagine his face. And we can imagine that we desire something - in an effort to understand the public's reaction to a particular political candidate, I might imagine myself wanting that candidate to win.

But despite all of these natural connections between imagining and desiring, there are several surprising aspects to the way that desire works in imaginative contexts. Reading Harry Potter and the Sorcerer's Stone, I imagine the Quidditch match between Gryffindor and Slytherin. I picture Harry on his Nimbus 2000, searching for the Snitch, while the Gryffindor Beaters ward off the Bludgers. And I also want Gryffindor to win the match. But how can I have this desire? Though it is structurally parallel to my desire that the Mets beat the Marlins, I know that the Mets, unlike the Gryffindor Quidditch team, really exist.

Consider also the role of desire in motivating action in imaginative contexts. While playing cops and robbers, one child points her finger at another and says 'bang.' Part of what motivates her action is that she imagines him to be a robber. What's the rest of the story? Is it that she wants to shoot him? This seems rather unsatisfactory-when a young girl plays cops and robbers with her brother, for example, she presumably doesn't (usually, anyhow) have the genuine desire to shoot him. Is it that she wants to pretend to shoot 
him? This too seems rather unsatisfactory-in playing the game, she might become so immersed in her activity that she loses herself within it.

In these ways, desire behaves oddly in imaginative contexts. Sometimes in imaginative contexts-in particular, when we are engaging with works of fiction-we have desires that are difficult to explain, at least given our traditional understanding of what a desire is. Call this the problem of conative engagement. ${ }^{1}$ Sometimes in imaginative contexts-in particular, when we are pretending - we take actions that are difficult to explain, at least given our traditional understanding of belief-desire explanations of actions. Call this the problem of motivation. The problem of conative engagement and the problem of motivation are often taken to be closely related-indeed, as merely two different strands of a single underlying problem-so I will refer to them jointly as the puzzle of imaginative desire. ${ }^{2}$

In an attempt to solve this puzzle, some philosophers have recently claimed that accounts of these imaginative contexts should not invoke desire at all. The mental state doing the work is not really a desire but rather a desire-like state that serves as the imaginative analogue of desire. There's a difference between believing that Harry Potter is flying overhead on his Firebolt and imagining that Harry Potter is flying overhead on his Firebolt; likewise, there's a difference between wanting the Gryffindors to win and imaginatively wanting the Gryffindors to win. This state of imaginatively wanting is sometimes called a make-desire [Currie 1995], sometimes a desire-like imagining [Currie 2002; Currie and Ravenscroft 2002] and sometimes an i-desire [Doggett and Egan 2007]. I will adopt this last terminology in what follows. ${ }^{3}$ The attempt to solve the puzzle of imaginative desire by postulating i-desires is what I will call the $i$-desire solution. ${ }^{4}$

Proponents of i-desires don't tell us much about what they are, but here's what we know: I-desires are meant to be novel mental states. An i-desire is not a special kind of desire or a subset of desire proper but rather a special kind of imagining that has too often gone unrecognized [Currie and Ravenscroft 2002: 20]. Just as we have imaginings that are belief-like, we also have imaginings that are desire-like. When I have an i-desire, I am not imagining that I want something; the act of i-desiring that the Gryffindors win is different from the act of imagining that I want the Gryffindors to win. The first is a desire-like

\footnotetext{
${ }^{1}$ This problem is roughly what Currie [1997] has called the paradox of caring.

${ }^{2}$ This name might evoke the puzzle that Gendler [2000] has called the puzzle of imaginative resistance (the term 'imaginative resistance' appears first in Moran [1994]). The question of the relationship between these two puzzles is an interesting one that I will unfortunately be unable to address here.

${ }^{3}$ This terminology has the unfortunate implication that our mental states are products developed by Apple (e.g., the iDesire), but there's also a more important reason to be careful about it: The term 'i-desire' might tempt one to think of the mental state of imaginatively wanting as a special kind of desire. This temptation must be resisted; idesires are by definition not desires.

${ }^{4}$ A similar move is also made by proponents of simulation theory in the theory of mind debate. According to simulation theory, we understand the minds of others by simulating their mental states. The simulated desires that we produce are often referred to as pretend desires or off-line desires. See, e.g., Gordon [1986]; Goldman [2006]. It's plausible that these pretend desires are equivalent to i-desires. For example, Currie, a proponent of the i-desire solution to the puzzle of imaginative desire, is also a simulation theorist. See Currie and Ravenscroft [2002]; also Doggett and Egan [2007: 16].
} 
imagining about the Gryffindors; the second is a belief-like imagining about me and my wants. Finally, just as beliefs and (belief-like) imaginings are distinguished from one another by their functional roles, so too desires and i-desires are distinguished from one another by their functional roles. As Doggett and Egan describe it, the functional role played by i-desires is 'analogous to, though not the same as, that played by desires' [Doggett and Egan 2007: 9].

In this paper, I will argue that we should reject the i-desire solution to the puzzle of imaginative desire. Avoiding i-desires has the advantage not only of ontological parsimony but also, more importantly, of allowing us to make better sense of what we are doing when we engage with fiction and play games of pretend. However puzzling the role of desire in these imaginative contexts, it is indeed desire-and not some novel mental state like an idesire-that plays a role.

\section{The Problem of Conative Engagement}

Suppose I am watching a stage performance of Peter Pan. Tinker Bell has just selflessly drunk some poisoned medicine intended for Peter, and she is dying. Peter explains to the audience that fairies are sustained by the beliefs of others; to save Tinker Bell, we all must clap our hands to show that we believe in her. I start to clap. So does my four year old son sitting next to me. How are our actions to be explained? My son doesn't yet have a great grasp of the difference between reality and make-believe, and he doesn't fully understand that the characters in the performance are 'just pretend.' So, watching the events on stage and taking them to be real, my son claps his hands because he believes (falsely) that Tinker Bell exists, he believes that she's dying, and he wants to save her. My action can't be explained the same way. I do know that Tinker Bell is just pretend. Still, I might clap my hands because I want to follow the conventions of watching Peter Pan; audience members are supposed to clap at this point in the show, and I know this. Or perhaps I believe that refraining would spoil things for my son, and I don't want to do that. Either way, my action has a perfectly respectable and ordinary explanation.

My son's action is explained by invoking his desire that Tinker Bell be saved; mine is not explained in the analogous way. But that doesn't mean that I don't have the desire. I share that desire with my son, and probably with most of the other teary-eyed members of the audience-both parents and children alike. I also don't want the Darling children to be kidnapped by Captain Hook, I want Peter Pan to rescue them, and I wish that they could stay with him in Neverland rather than return home. Surely this is a plausible description, at least pretheoretically, of the mental states of almost anyone in the audience who is paying attention. How could you watch Peter Pan and not want Tinker Bell to live? How could you not want Peter to rescue the Darlings from Captain Hook's clutches?

Unlike my son, I do know that the events depicted on stage are just pretend. So how can I have all these desires about characters that I know do not exist? An obvious suggestion at this point is that we've misinterpreted my desire. It's not that I want Tinker Bell to be saved; rather, I want it to be the case that in the fictional story being performed Tinker Bell be saved. Reinterpreting my desire as a desire about the fiction, however, just doesn't seem to capture accurately what I want. My desire isn't about the fiction; it's about 
Tinker Bell. One way to see this is to compare my desire to my son's desire. To my mind, there seems an important sense in which our desires about Tinkerbell are the same, i.e., an important sense in which we both want the same thing. My son isn't desiring something about the fiction - in fact, he doesn't even really understand that it is a fiction. As we have already granted, he is unproblematically desiring something about Tinker Bell herself. When he turns to me during the tense moments where her fate is up in the air, and he says, 'I don't want Tinker Bell to die, Mommy,' and I respond, 'I don't either,' it seems like we are in sync with one another, or at least, more in sync than is allowed by the reinterpretation strategy. ${ }^{5}$

The failure of the reinterpretation strategy leaves us without a way to understand the mental states in question. Though they appear to be desires, they don't behave like genuine desires. Three different reasons are invoked to support this claim: (1) These mental states violate the normative constraints governing desires; (2) these mental states do not motivate actions in the way that desires normally do; and (3) there is no adequate way to understand the contents of these mental states if they are genuine desires. Thus enters the i-desire. Proponents of i-desires claim that if we understand the mental states in question as i-desires-mental states that are desire-like without being genuine desireswe no longer have any problem making sense of their unusual characteristics.

In what follows, I want to take a closer look at these three reasons. What I hope to show is that none of them requires that we accept the existence of i-desires. In each case, there is a perfectly respectable way to explain the character of the mental state that is compatible with its being understood as a genuine desire.

\subsection{Normative Constraints}

The first reason offered in support of the i-desire solution is that the usual normative constraints governing desire do not apply-or, at least, do not always apply-in imaginative contexts. According to Currie, 'Desires can be shown to be unreasonable, or at least unjustified, if they fail to connect in various ways with the facts.' [Currie 2002: 211] His own example concerns the desire to see someone punished, a desire whose reasonableness depends on the facts about what they did. Suppose I come home to find my house a complete mess-books have fallen off the shelves, there's broken glassware everywhere, etc. It seems perfectly reasonable that I want to see the perpetrator punished. If I then discover that the situation was caused by an earthquake, and thus that there was no perpetrator, the desire is no longer rational; its reasonableness is undercut by the fact that no such person exists. Now consider my desire that Captain Hook be punished for taking the Darling children from the Lost Boys encampment and bringing them to his ship.

\footnotetext{
${ }^{5}$ The fact that my son and I have different beliefs about Tinkerbell's existence means that our desires are unlikely to have exactly the same content and thus that we cannot be perfectly in sync. However, insofar as my desire differs from my son's, this seems like the perfectly familiar fact that our desires reflect our conceptions of things. For example, my son's desire that a particular candidate win the election might not have quite the same content as my own desire about that candidate. Since I know much more about the candidate than he does, the content of my desire might be fuller, or more rich. In contrast, once we employ the reinterpretation strategy, it's not just that my desire has a content slightly different from my son's; rather, it becomes a desire of a different type. This seems to make too sharp a differentiation between my desire and my son's. Thanks to Suzanne Obdrzalek for pressing me to clarify this point.
} 
This desire also seems reasonable, but unlike the reasonableness of my desire about the mess-maker, the reasonableness of my desire about Captain Hook 'is not undercut by the fact that there is no such person as [Captain Hook], and so no such person ever did anything deserving of punishment.' [Currie 2002: 211] ${ }^{6}$ Thus, Currie argues, our apparent desires about fiction depart from the usual normative constraints governing desire.

To see the difficulties with this reasoning, it is useful to step outside the realm of fiction for a moment. We have all sorts of genuine desires about things that are not actual: desires about past events and existents, desires about future events and existents, desires about counterfactual events and existents, and so on. I might desire that I could introduce my children to their grandfather, who is no longer living; I might desire that my (not yet existing) grandchildren have healthy and happy lives; I might desire that a certain ballot proposition had been defeated in a recent election. ${ }^{7}$ In none of these cases is the reasonableness of the desire undercut by the fact that the object of the desire is nonactual.

Perhaps none of these cases provides a perfect parallel to the case of fiction. But by reminding ourselves that there is a large range of cases in which we have desires about nonactual entities and events, we can more easily see that our desires about fictional entities and events are not especially peculiar; they simply lie along the same continuum as our desires about the past, the future, and the counterfactual. Moreover, I assume that we have no temptation whatsoever to view these other sorts of desires about the nonactual as i-desires. In fact, such desires are so commonplace that it is almost impossible to raise an air of paradox about them. If these desires about the nonactual are unproblematic, then what makes our desires about fictional characters any different? At the very least, the normative constraints that govern desire are considerably more complex than is here being supposed by the proponent of i-desires.

\subsection{Inaction}

The second consideration offered to show that we must invoke i-desires to solve the problem of conative engagement is that these mental states are not connected to action in the way that desires typically are. As Currie argues, exercises of the imagination 'can't involve really taking on a new desire, exactly because desires have connections to actions; if imagining led me to have desires appropriate to a merely imagined situation, I might end up acting in dangerous ways.' [Currie 2002: 211] ${ }^{8}$ Normally, if you see someone in trouble, and you have a desire that they not be hurt, you do something: You intervene, call 911, run to get help, etc. My desire that the Darling children not be kidnapped by Captain Hook doesn't prompt me to do any of those things when I see it happening. Rather, I just sit passively in my seat.

\footnotetext{
${ }^{6}$ Currie's own examples are drawn mainly from Shakespeare. In the quoted passage, he is concerned with the reasonableness of our wanting punishment for Desdemona compared to the reasonableness of our wanting punishment for Macbeth.

${ }^{7}$ In a discussion of our emotional responses to fiction, Moran notes that we experience all sorts of emotional reactions about things that are non-actual. The fact that our emotions about what might have been are entirely unparadoxical should, Moran suggests, help to dissolve the sense that our emotional responses to fiction are paradoxical [Moran 1994: 77-78]. As I suggest in the text, I think these points apply equally well to our conative attitudes to fiction.

${ }^{8}$ See also Doggett and Egan [2007: 6]. 
The standard picture of desire sees it as essentially motivational; roughly put, to desire that $\phi$ is to be disposed to bring it about that $\phi$. Given this standard picture, my inaction is puzzling. Proponents of $\mathrm{i}$-desires thus suggest that the best way to explain my inaction is to deny that I have a genuine desire that the Darling kids not be kidnapped; rather, this is something merely $\mathrm{i}$-desired. By definition, $\mathrm{i}$-desires have different functional roles from desires. We are not really told anything definitive about what this functional role is, but let's just grant for the moment that a complete story of i-desires yields the right result here. So the suggestion is that while my inaction is inexplicable on the assumption that I desire that the Darlings not be kidnapped, it becomes easily explained on the assumption that I i-desire that the Darlings not be kidnapped.

To reject this reasoning, it will be helpful to look at some potential counterexamples to the standard picture of desire, i.e., examples that suggest we should loosen the connection between desire and its motivational tendencies. Alfred Mele has suggested that, in rare cases, desires may be motivationally inert. When I am on my way to the airport to pick up a friend, I might wonder whether her plane departed on time, and I might desire that her plane departed on time, but as Mele says, 'this desire in no way disposes me to bring it about that the plane left on time since it does not dispose me to endeavor to change the past.' [1995: 394] ${ }^{9}$ Tim Schroeder, who goes yet further than Mele in arguing that motivation is not essential to desire, claims that cases of motivationally inert desires need not be so rare. Consider an ancient Greek mathematician who, though uncertain about the value of $\pi$, desires that it not be expressible as a fraction of two natural numbers. This doesn't incline him towards any particular behavior. Like this mathematician, we have all sorts of desires for ends that we can do nothing about: Someone might desire that she had never been born, or that her parents had never met, or that a committee make a decision in her favor without her having to intervene. [Schroeder 2004: 16-7]

Rejecting the standard picture of desire is quite controversial, but fortunately, for my purposes here, I need not take a stance on whether these potential counterexamples force us to that conclusion. Perhaps they can be accommodated by the standard theorist, but in that case, the standard theorist will presumably also be able to accommodate the desires that we have toward fictional characters. The thrust of the potential counterexamples is to remind us that our inability to change a situation need not deter us from forming desires about it. Just as I cannot control past events, I cannot control the course of the fictional events-but in neither case am I stopped from forming desires about them.

Presumably, I don't act to change the past even when I desire to do so because I don't believe that there is anything I can do. This reasoning also explains why I don't act to do anything about fictional danger. When reading a book or watching a movie, we typically cannot take any actions to stop the course of the fiction from unfolding. Perhaps there are

\footnotetext{
${ }^{9}$ While this desire does not motivate me to bring it about that her plane departed on time, it might have other motivational consequences, for example, it might lead me to make various utterances, e.g., 'I hope that her plane departed on time.' Mele adduces further (much more complicated) examples to show that desires can be entirely inert, lacking even these motivational consequences; see Mele 1995, 394-396. Joel Marks also argues that desires need not be inherently motivational; on his view, 'motivation is conceptually tied to action, while desire is not. For example, one cannot be motivated that it be a nice day, for its being a nice day is not a possible act. ... But one can certainly desire that it be a nice day.' [Marks 1984: 140]
} 
actions we can take when watching a play; I might jump on stage and stop the actors from doing what they're doing. Here some considerations from Peter Carruthers will be useful. Carruthers has suggested that we don't act to stop fictional danger because 'real desires will normally lead to real action only when interacting with real beliefs.' [Carruthers 2006: 99] When watching the play, I am imagining, not believing, that the Darlings are being kidnapped by Captain Hook. ${ }^{10}$ Since my desire that they not be kidnapped will lead to action only in conjunction with relevant beliefs, there is no difficulty in explaining why I do not leap to their rescue while watching the play. In the absence of any real beliefs about their situation, my desire's failure to lead to action is not anomalous. Rather, it fits perfectly the functional profile of a genuine desire.

\subsection{Content}

In their recent paper arguing for the existence of i-desires, Doggett and Egan present a third reason in support of the i-desire solution: We cannot adequately specify the content of the mental states if they are understood as desires. ${ }^{11}$ Consider my desire that Peter be victorious over Captain Hook, or my desire that the Darling children stay in Neverland at the end of the play. What are these desires really about? One natural suggestion treats them as de re desires about fictional characters, the first about the fictional character Peter Pan and the second about the fictional Darling children. ${ }^{12}$ This suggestion raises worries about the ontology of fiction, but even if we set such worries aside-that is, even if we grant for the sake of argument that there are fictional characters for us to have de re desires about-Doggett and Egan claim that understanding my mental state this way cannot adequately capture what I seem to desire. ${ }^{13}$

Take my desire that the Darling children do not return to London at the end of the play, that is, my desire

(1) that the Darling children remain in Neverland.

\footnotetext{
${ }^{10}$ Carruthers' reply presupposes the pretence theory of fiction, i.e., that we engage with works of fiction via our imagination. For a defense of the pretence theory, see, e.g., Walton [1990] or Currie [1990]. Though I personally have reservations about this theory, proponents of i-desires can raise no complaints about its invocation here since they are themselves committed to it.

${ }^{11}$ This point relates to the failure of the reinterpretation strategy that we considered earlier. See also n. 15.

12 Doggett and Egan consider and reject two other suggestions: My desire that Peter Pan beat Captain Cook might be (1) a de dicto desire that people who fit Peter Pan's general description be victorious in that sort of situation; or (2) de re desire about some actual boy named Peter Pan who wouldn't grow up. I agree with them that both these suggestions are non-starters. I might desire that Peter Pan take the Darling children with him to Neverland, but I certainly don't desire that real life individuals dressed similarly to elves take children from their bedrooms at night, and even if, coincidentally, there really is some real-life boy named Peter Pan, my desire is not about him.

${ }^{13}$ I should note that Doggett and Egan have not specified the problem of conative engagement quite the same way that I do, and thus my presentation of their argument departs slightly from what they actually say. To avoid begging any questions, rather than focusing directly on our conative attitudes to fiction, they raise the concern indirectly by way of our emotional responses to fiction. Watching Peter Pan, you are filled with anxiety that Tinker Bell might die. They argue, and I agree, that 'something like a desire is needed to produce affective response when you are anxious about something that you are imagining.' [Doggett and Egan 2007: 13] They then adduce the reasons I outline in the text above to show that no actual desire you have has adequate content to produce this anxiety.
} 
Understood as a de re desire about fictional characters, this desire has the content

(1a) that the fictional characters the Darling children remain in Neverland. Doggett and Egan claim that desiring (1a) entails that we must also desire

(2) that the fiction be such that the Darling children remain in Neverland. The only way for the fictional Darlings to remain in Neverland would be for the fiction Peter Pan to have them stay in Neverland. If my desiring (1a) didn't entail my desiring (2), then I would be irrational, yet there seems to be no irrationality involved in desiring (1a). As they put the point:

Having the desire about the fictional character entails, or at the very least rationally requires, that one have the corresponding desire about the content of the fiction, since the only way for the fictional character to have the property that we desire him to have is for the content of the fiction to make it so. [Doggett and Egan 2007: 14]

On their view, however, this entailment is problematic. Even if I desire that the Darlings stay in Neverland, I might fully recognize that it makes for a better story if the Darlings return home. Thus, since desiring (1a) rationally requires that we desire (2), but since we might desire (1) without desiring (2), we should not understand (1) as (1a), i.e., (1) is not a de re desire about a fictional character.

Certainly, one doesn't want to defend the claim that mental states like (1) are genuine desires if the cost is sacrificing our rationality, but I'm not so sure that it is. Consider a mother whose only child is a senior in high school. She wants her son to go away to college and she firmly believes that certain experiences can only be achieved if he does. Simultaneously, she fears having an empty nest, and thus she also wants her son to stay home and attend a local school. Does this make her irrational? Surely not. Rather, it seems like a perfectly ordinary case of conflicting desires.

Doggett and Egan's argument that desiring (1a) rationally requires my desiring (2) seems plausible only because they are smuggling in a consistency requirement about desires. ${ }^{14}$ The mother's desire not to have an empty nest does not rule out her also having the desire that he go away to college; rather, she might have inconsistent desires. Likewise, my having the desire that the fictional Darling children remain in Neverland does not entail my having the desire that the fiction have them remain in Neverland; ${ }^{15}$ rather I might have inconsistent desires. Moreover, in neither case is it irrational to have inconsistent desires. Part of what's so hard about having desires is that we don't get to satisfy them all.

\section{Resisting i-desires}

It's time to take stock. As I have argued, none of the reasons canvassed above supports the invocation of i-desires in order to account for our conative engagement with fiction. Given

\footnotetext{
${ }^{14}$ I am indebted to Peter Kung for this suggestion.

${ }^{15}$ As this should make clear, in claiming that our desires can be desires about fictional characters, I am not embracing the reinterpretation strategy we rejected earlier. The reinterpretation strategy claims that (1) can be reinterpreted as (2) - my desire about Wendy Darling is best understood as a desire about the fiction in which she appears. I claim only that (1) can be reinterpreted as (1a) — my desire about Wendy Darling can be understood as a desire about the fictional character Wendy Darling. Importantly, I deny that (1a) entails (2), and thus a fortiori I deny that (1a) can be reinterpreted as (2).
} 
that i-desires were introduced in this context solely because they seemed to solve the problem of conative engagement, we have not as yet been given any reason to believe that there are any such mental states. There is still the problem of motivation to consider-that will be the subject of our next section. But before turning to that problem, I want to make a more general point. To my mind, our conative engagement with fiction not only fails to require the introduction of i-desires but also provides us with positive reasons to avoid doing so.

Here I have in mind reasons other than simply those of mental economy-though of course, if we can make do perfectly well without postulating a novel mental state, we should refrain from doing so. Rather, I am interested in the deeper issue about what's at stake if we accept the existence of i-desires. Brief reflection on this issue shows that there are several strong reasons to resist the suggestion that we don't experience genuine desires, but only imaginative analogues of them, in our conative engagement with fiction.

First, note that in most circumstances, our belief-like imaginings don't seem to us to be beliefs. We know the difference between believing something and merely imagining it. ${ }^{16}$ Thus, one would expect us to be able to tell the difference between desiring something and merely i-desiring it. But this does not seem to be the case. Generally, when we engage conatively with fiction, we take ourselves to be having real desires. The only way I can tell that I am i-desiring something, rather than really desiring it, would be to infer it from the fact that the subject of my desire does not exist. In contrast, no such inference is required to know that I imagining something rather than believing it.

The fact that we take ourselves to be having real desires when we conatively engage with fiction does not itself show that this engagement does not involve i-desires; after all, idesires might feel subjectively just like desires. An illusion might feel subjectively just like a perception, but the two are distinguished by the ontological status of what they purport to represent. The situation might be similar with respect to i-desires and desires. ${ }^{17}$ If it is, however, then the proponent of i-desires must claim that we are systematically mistaken when engaging with fiction about the kinds of mental states that we are having. Though it feels to us that we are having desires, we are really having i-desires. One doesn't have to endorse any strong thesis of privileged access to feel queasy about this. Of course, there might be times when our therapists know better than we do what we really desire, and we might sometimes be surprised to realize that our behavior suggests that we have desires that we didn't realize we had. So we might sometimes fail to recognize desires that we have. There are also times that we mistake the kind of state that we're in-as when two people fail to recognize that their strong reaction to one another is love, not hate. All of these cases, however, are exceptions to the norm. When evaluating our mental attitudes, we are normally reliable discerners of what kinds of mental attitudes we are having, and we normally can do it directly, without having to know anything in particular about the outside world or about what other activities we are involved in. Thus, when we're choosing among theories, one that doesn't have us systematically mistaken about what

\footnotetext{
${ }^{16}$ This is not meant to be a phenomenological point, i.e., I am not presuming that we can phenomenologically tell the difference between believing $p$ and imagining $p$. For my purposes, it doesn't matter how we make the differentiation. All that matters is that we do it and that we do it non-inferentially.

${ }^{17} \mathrm{I}$ am grateful to an anonymous referee for pushing me on this point.
} 
mental states we're having is surely to be preferred, other things being equal, to one that does have us making such systematic errors.

The second reason to avoid the postulation of i-desires stems from a set of considerations concerning the way we normally regard our desires about fiction, about the way they function in our assessments of ourselves and others. ${ }^{18}$ Consider the fact that we take evaluative stances towards our conative responses to fiction. When watching the Woody Allen movie Match Point, I was incredibly anxious about the fate of Chris Wilton, a former tennis pro who ends up murdering his pregnant mistress because she's pressuring him to leave his wife. I wanted him to escape capture by the police. Thinking about the movie afterward, it bothered me that I could have had this desire-that I could have found a murderous adulterer so sympathetic. Likewise, when watching the stellar HBO series The Wire, I found myself rooting for Baltimore Detective Lester Freamon in his attempts to set up an illegal wiretap on the local drug kingpin. As the storyline unfolded over several episodes, I wanted the wiretap to work, and I wanted it to remain undiscovered by Freamon's superiors. Again, thinking about the show afterward, I was bothered by my own reaction to it. Yes, Freamon is a sympathetic character, but why did I want him to break the law? In real life, I certainly don't approve of illegal activity by police detectives, even those attempting to apprehend violent criminals of the sort that Freamon was after. In real life, I don't want the police to employ illegal means in their efforts to protect and serve, and I don't want their legal powers expanded. So I puzzled over why I would have wanted Freamon to succeed.

Forget for the moment the specific contents of the conative attitudes that I had in response to these works of fiction, however puzzling they might be. ${ }^{19}$ Focus instead on my evaluative reactions afterwards. Why was I bothered by these apparent desires? Why did they puzzle me? Insofar as I'm worried about what they say about me as a person, it's most plausible that I'm seeing them on a par with other desires that I have. The best way to make sense of my self-evaluation and self-criticism is to see my apparent desires concerning the fictional characters as genuine desires.

\footnotetext{
${ }^{18}$ In putting forth these considerations about our conative responses to fiction, I am indebted to Moran's use of parallel considerations about our emotional responses to fiction [Moran 1994]; Moran sets out these considerations in an attempt to call into question the view advocated by Walton [1990; 1997] and others that such responses are not full-fledged emotions. In his enormously rich discussion, Moran notes that the fact that someone can make disturbing discoveries about himself by considering his emotional reactions to fiction only makes sense if those reactions are genuine emotions: 'Such reactions would be hard to understand if what he felt was as remote from his real temperament as the events on the screen are remote from his real beliefs about the world.' [1994: 93] Moran also notes that our 'ordinary practice of eliciting, sharing, and criticizing such emotional responses to fictions would be a quite bizarre and pointless exercise if these responses and the attitudes they express were not located on this side of the counterfactual divide', and thus concludes that 'it is less misleading to see them as different types of, for example, pity, rather than to think of the difference as akin to that between a real horse and an imaginary one.' [1994: 94]

${ }^{19}$ The puzzling nature of these reactions is what Currie has called the problem of personality: 'The desires we seem to have concerning fictional things can be very unlike the desires we have concerning real life-so dissimilar, indeed, that it is hard to see how such disparate desires could exist within any reasonably integrated human mental economy.' [1997: 65] This seems to me to overstate the case, however, and again to smuggle in some kind of consistency requirement about desires.
} 
Moreover, just as we take ourselves to task for our conative responses to fiction, we take others to task as well. We would consider it disturbing if a viewer of Peter Pan wanted Tinker Bell to be killed, or wanted the Darling children to be hurt by Captain Hook. In fact, if a friend told me that she didn't care whether Tinker Bell lived or died, I would reconsider my opinion of her. But when we criticize one another for not caring-or for caring too much-about a character or event, the critical interest we take in one another's conative attitudes can be best understood by viewing the conative attitudes as genuine. Even the fact that we talk to one another so much about our conative attitudes to fictions-that when we exit a movie theater, we discuss with one another not only the intricacies of the film's plot but also our attitudes towards the characters-shows that we are taking those attitudes seriously-a seriousness that would not be warranted if they were merely desirelike imaginings. We don't treat one another's belief-like imaginings with this sort of seriousness. ${ }^{20}$

Both our own sense of our desires and a large set of practices surrounding them therefore support the fact that the desires are genuine. Thus, as I've hoped to show in this section, not only do we lack good reasons for adopting the i-desire solution to the problem of conative engagement, but we also have good reasons for resisting it. At least with respect to this problem, positing i-desires does not give us any extra explanatory power, and it robs us of explanatory power with respect to a large web of commonplace intra- and interpersonal practices.

\section{The Problem of Motivation}

The problem of conative engagement tends to be raised in the context of what I'll call passive imaginings-when we are spectators at a play or readers of a novel. With this terminology I don't mean to suggest that these imaginings happen to us-we are not passive in that sense. ${ }^{21}$ Rather, the sense of passivity that I have in mind is that we typically do not engage in these imaginings by performing any bodily actions. Contrast this with children's games of pretence, which are taken to involve paradigm cases of what I'll call active imagining. Active imaginings are brought about in conjunction with physical activity. ${ }^{22}$ A child imagining herself to be a cop points her finger at the pretend robber. An actress imagining that she has been betrayed uses body language to communicate this. The

\footnotetext{
${ }^{20}$ Imaginings with either sexual or violent content might seem to constitute an exception to this claim; such imaginings might often seem to be taken quite seriously. When we do so, however, our reactions depend primarily on the way that the imagining is viewed by the imaginer, i.e., by the (genuine) attitude that the person takes towards her imagining. What matters to us is not, for example, that someone spontaneously imagines some horrific violence but that she enjoys doing so. (Thanks to an anonymous referee for this suggestion.) See also fn. 26.

${ }^{21}$ In fact, on my view, imagining is best understood as an active mental exercise. This is part of how it differs from perception. See Kind 2001.

${ }^{22}$ I here mean to be deliberately neutral on whether the imagining happens first, followed by the pretend behaviour, whether the reverse is true, or whether the imagining and the behaviour happen concurrently. For our purposes here, this need not be settled. I will return to this issue in Section 5 below.
} 
problem of motivation typically arises in the context of these kinds of active exercises of imagining.

Consider a standard case of a child pretending to be something that he's not. Almost every morning when my younger son wakes up, he pretends that he's a cat or a dog. Today was a dog day; when I entered his room, he greeted me with a 'woof woof'. Now my son doesn't believe that he is a dog; that is something that he only imagines. So what motivates him to bark? This is the problem of motivation: How are we to explain the fact that we are sometimes moved to act by something that we imagine but do not believe?

\subsection{The N-S schema}

Intuitively, this problem may seem to have an easy solution. Our actions in such cases are motivated by desires to engage in behavior (which I refer to as pretend behavior) that in some way promotes the scenario we are imagining. When my son imagines that he is a dog, he wants to act as dogs act. Given that he believes that dogs say 'woof woof', his desire to act like a dog motivates him to say 'woof woof'. Developing roughly this suggestion, Nichols and Stich present us with a schema-what I will call the $\mathrm{N}$-S schema-according to which pretend behavior can be explained by:

1. the desire to behave similarly to how one would behave were an imagined situation actual

2. beliefs about what the relevant behavior would be in an actual situation. On their view, a child who wants to pretend that he is a dog calls upon his beliefs about dog-like behavior and behaves 'more or less' as he would if he were a dog [Nichols and Stich 2003: 39]. The qualifier is necessary because pretenders often have good reasons not to behave exactly as they would behave were the pretend scenario actual. When my son pretends to be a terrible monster, he doesn't actually bite me as he believes the terrible monster might. ${ }^{23}$ When someone pretends that there is a burglar in the basement, she doesn't actually call 911. If she picks up the phone, she will only pretend to push the buttons, for example, or she won't hit send.

Against this view, Doggett and Egan have charged that 'you do not need to have any beliefs about how something behaves (or is disposed to behave) in order to pretend that you are that thing. You certainly needn't have any beliefs that are sufficiently determinate to call for any specific behavior.' [Doggett and Egan 2007: 5] For many cases of pretending, this claim seems implausible to me. Can we really pretend to be something without knowing anything about how it behaves? Can my son pretend to be a vervet, given that he has no idea what a vervet is? In other cases, however, Doggett and Egan's point has more force. Consider their case of somebody pretending to be a member of the undead by walking stiffly with her arms stretched straight out ahead. She might do so without having any beliefs about how the undead act and perhaps even any beliefs about the undead at all. Rather, she simply draws on the conventions for pretending to be undead.

Let's grant that this example shows that there are some cases of pretend behavior for which the N-S schema fails. This, however, demands the move to i-desires only if we make the unwarranted assumption that there must be a single explanatory belief-desire

\footnotetext{
${ }^{23}$ I have, however, seen children pretending to be 'biting monsters' whose parents end up with tooth marks on their legs. I return to this example in section 5, below.
} 
schema for all pretend behavior. The N-S schema does not explain every case of pretend behavior, but why would we think that it would? ${ }^{24}$ More plausibly, in my view, different types of belief-desire explanations are at work in the many varied cases of pretending.

Sometimes, our actions can be explained by a desire to behave similarly to how we would if some imagined scenario were actual, as Nichols and Stich suggest. Sometimes, a different desire motivates us: namely, a desire to behave similarly to what conventions dictate about the imagined scenario. This is what happens in the case of pretending to be the undead. And sometimes yet a different desire might motivate us. For example, my younger son's pretend behavior is sometimes best explained by his desire to do whatever his older brother is doing. In short, the failure of the N-S schema to account for every case of pretend behavior does not mean that some cases of pretend behavior escape beliefdesire explanation altogether.

\subsection{The depressing objection}

Given the line of argument presented above, we now face a deeper, more general worry, one that dates back at least to Gilbert Ryle's discussion of pretence in The Concept of Mind. As Ryle notes, while there are some varieties of pretending in which the pretender remains aware of the role being played throughout the entire course of the pretence, there are also other varieties in which 'he is completely taken in by his own acting.' [Ryle 1949: 258] As an example of this latter variety, Ryle asks us to consider 'the child playing bears, who knows, while in the well-lit drawing room, that he is only playing an amusing game, but feels faint anxieties when out on the solitary landing, and cannot be persuaded of his safety while in the darkness of a passage.' [Ryle 1949: 258] This leads Ryle to a constraint on any adequate theory of pretence: We must be able to account for the fact that children can play games of pretence with complete credulity in the games that they are playing, i.e., without always being aware that they are playing games at all.

Unfortunately for my argument here, this Rylean constraint seems to count against belief-desire explanations of pretend behavior. Velleman [2000: 257-8], who has forcefully developed this line of argumentation, claims that adopting any belief-desire explanation of pretend behavior treats the child engaging in pretence as 'depressingly unchildlike'. When we explain pretend behavior in terms of beliefs and desires, there is no way to avoid the fact that those beliefs and desires will be about what's being pretended. As a result, they seem to locate the pretender firmly outside his pretence, overintellectualizing his behavior. These considerations, which I will call the depressing objection, lead Velleman to conclude that children often act on the basis of 'mock-desires' that are not themselves desires. ${ }^{25}$

\footnotetext{
${ }^{24}$ Given the functional architecture of their system, Nichols and Stich themselves might have reasons to believe that it would, but there is no special reason for us to accept that overarching architecture.

${ }^{25}$ For Velleman, these mock-desires are called wishes. As best as I understand his view, wishes are not quite what Doggett and Egan have in mind by i-desires [Doggett and Egan 2007: 10-1]. Desires and wishes are both members of the same class of mental state-they are both 'conations' [Velleman 2000: 260]. According to Velleman, what distinguishes them is that desires can (at least usually) only be directed at things that at least have the appearance of being attainable, whereas wishes are directed at things that we know to be unattainable. I'm skeptical, as are Doggett and Egan [2007: 11], that Velleman is right that we cannot desire what is 'patently unattainable,' but that is not important for our purposes here. What is important is that we keep in mind that desires and i-desires are not members of the same class of mental state, and they are not meant to be distinguished from one another in terms of the attainability of their aims.
} 
Doggett and Egan raise similar worries against belief-desire explanations of pretend behavior in support of the i-desire solution to the problem of motivation. In their view, a belief-desire explanation of some instance of pretend behavior treats the pretender analogously to 'an actor who consults his beliefs about how he should play a role'. [Doggett and Egan 2007: 8] When I am pretending to be a dog, I must think to myself: What would a dog do here? Or: What would our conventions dictate that someone pretending to be a dog would do here? But, as they note, this seems psychologically implausible. When engaging in pretend behavior, we often 'lose ourselves' in what we're pretending. We need not first consult our beliefs about how dogs act or what conventions dictate; rather, we simply slip into the role of being a dog.

Admittedly, belief-desire explanations of pretend behavior do often sound like rather implausible descriptions of what people engaging in pretence are consciously doing, but of course, there's no reason we must maintain that the beliefs and desires posited by these explanations are conscious beliefs and desires. We explain ordinary behavior all the time in terms of non-conscious beliefs and desires. Why should pretend behavior be any different? Doggett and Egan explicitly recognize this point and insist that what they find psychologically implausible is that one would have to have these beliefs and desires at all, consciously or not [Doggett and Egan 2007: 8-9]. Once we recognize that the relevant beliefs and desires need not be conscious, however, their objection seems to me to lose much of its force.

The belief-desire explanations of pretend behavior may, as Velleman says, seem to make the child pretender out to be 'depressingly unchildlike'. This, I think, is at least partly due to the process of specifying any explanation at all. Whenever we make explicit the nonconscious thoughts that lead to action we introduce an element of artificiality that strikes us as implausible. Actions that seem whimsical or spontaneous no longer retain that aura once we explicitly spell out the beliefs and desires that motivated them. The amorous behavior of a lover becomes depressingly unromantic; the comic behavior of the class joker becomes depressingly unfunny. The problem is not (or, at least, need not be) that the explanation goes wrong but rather that giving any sort of explanation demystifies the action and, in doing so, robs the action of its sense of romance, its comic elements, or its whimsy. ${ }^{26}$

My argument here gains support from some remarks of Currie and Ravenscroft who, though themselves proponents of i-desires, do not think that their case for the i-desire solution can be made on the basis of the depressing objection. In their view, Velleman's argument mistakenly suggests that someone whose pretend behavior is motivated by beliefs and desires must be thought of as either 'calculating' or 'dispassionate'. We often behave 'skillfully and creatively on the basis of beliefs and desires that make little or no conscious impact on us'. [Currie and Ravenscroft 2002: 124] Thus, even if our explanation of a child's behavior steps outside of the pretence, this is perfectly compatible with the child's being completely absorbed in his pretending.

\section{Resisting i-desires, round two}

${ }^{26}$ For a related argument against the depressing objection, see Funkhouser and Spaulding [2009]. 
As I have argued thus far, just as the proponent has failed to make his case that we must invoke i-desires to solve the problem of conative engagement, so too does he fail to make his case that we must invoke i-desires to solve the problem of motivation. Likewise, just I suggested above that we have positive reasons to avoid the i-desire solution when it comes to the problem of conative engagement, I now want to suggest that we have positive reasons to avoid the i-desire solution when it comes to the problem of motivation.

Suppose that one of my sons is pretending to be a terrible monster, and he's pretending that I'm his victim. He believes that terrible monsters bite, and so he approaches me while making chomping movements with his mouth. Even though he is playing a game of pretend, if he were actually to bite me, I would certainly hold him accountable for his behavior. If I try to explain the wrongness of what he did by telling him, 'We don't bite', his natural response will surely be, 'But terrible monsters do.' Thus, to make headway, I need to explain that, even when he's pretending to be a terrible monster, he shouldn't bite. In his pretend play, he's desiring to behave exactly like a terrible monster would behave-or as close to it as he can get-and I need to explain to him that this is a problematic desire for him to have. If he's going to continue to play games of pretend, at least in my household, he's going to have to lower his sights and learn to live with merely approximating the behavior of a terrible monster.

This description of my interaction with my son suggests that we hold people accountable for the conative attitudes motivating their pretend behavior in the same way that we hold them accountable for the conative attitudes motivating their ordinary behavior. Here we connect with an argument I offered above in the context of the problem of conative engagement: The best way to make sense of the fact that we hold people accountable for their apparent desires towards fictional characters is that those apparent desires are genuine desires. Likewise, the best way to make sense of the fact that we hold people accountable for the conative attitudes motivating their pretend behavior is that these attitudes are genuine desires, the same sort of conative attitudes that motivate ordinary behavior. We don't typically hold people accountable for things that they imagine, and as a general matter, at least, it's hard to see why we should. ${ }^{27}$ Seeing our pretend behavior as motivated by i-desires robs us of our ability to make sense of our normal evaluative practices.

A different problem arises from a dilemma faced by proponents of i-desires in specifying the content of the states that motivate pretend behavior. Consider how the proponent of i-desires explains the behavior of a child who, while pretending to be a bird, is flapping her arms in a bird-like way. It's unproblematic to suppose that she is imagining that she is a bird and imagining that she can fly. But what is the motivational state that interacts with these imaginings to explain the flapping of her arms? There seem to be two choices: It might be that the child i-desires to flap her arms, or it might be that the child idesires to fly. To my mind, neither of these choices proves satisfactory.

\footnotetext{
${ }^{27}$ Exceptions may arise from romantic fantasies. (Think of Jimmy Carter's famous Playboy interview in which he claimed that 'anyone who looks on a woman with lust has in his heart already committed adultery.') My guess is that these exceptions are explained by the fact that people often require especially stringent standards of faithfulness in their romantic relationships; one must be faithful not only in body but in mind and heart, too.
} 
Suppose that an i-desire to flap her arms motivates the child's behavior. The question then immediately arises: Why would she limit herself to such a meager i-desire? As we saw earlier, i-desires are free of the normative constraints to which desires are subject. Thus, even assuming that the child knows that it's physically impossible for her to fly, this should have no effect on what i-desires she forms; it should no more constrain her desire-like imaginings than it does her other imaginings. After all, the child is not just imagining that she's a bird-like human; she's imagining that she's a bird. And she's not just imagining that she can flap her arms in a bird-like way; she's imagining that she can fly. As Hume says in the Treatise, nowhere are we more free than when using the faculty of the imagination [Hume 1739/1978: 10]. We are remarkably unconstrained in the belief-like imaginings that we can have; we regularly imagine all sorts of things that we know to be untrue and even, in some sense at least, impossible. ${ }^{28}$ Desire-like imaginings should be analogously unconstrained. So it seems implausible that the child would motivate her pretend behavior solely by an i-desire to flap her arms. ${ }^{29}$

For this reason, we might expect to be better off if we explain the child's behavior in terms of the more full-blooded i-desire to fly. When children pretend to be fish, they idesire to swim underwater without taking breaths; when children pretend to be cheetahs, they i-desire to run as fast as cars; when children pretend to be birds they i-desire to fly; and so on. The problem with this suggestion, however, is that it doesn't do a good job of explaining the behavior that is actually produced. Remember that what the child is doing is flapping her arms. If the child was really i-desiring to fly, one would think that she would engage in different, more elaborate behavior: persistent arm-flapping, or running starts, or jumping into the air.

So the proponents of i-desires have no plausible way to specify the content of the idesires motivating pretend-behavior. On the first horn of the dilemma, they choose a content that matches well the behavior that is actually produced but this choice of content implausibly constrains the child's imaginative exercises. If there were such things as idesires, then surely children would i-desire to fly, not just to flap their arms. On the second horn of the dilemma, the proponents of i-desires choose a content that respects the

\footnotetext{
${ }^{28}$ Whether we can i-believe what we know to be logically or metaphysically impossible is controversial, but no one denies that we can imagine things that we know to be physically impossible.

${ }^{29}$ Despite this problem, I expect that Doggett and Egan would choose the route laid out by this first horn of the dilemma. On their view: 'pretend action is motivated by i-desires and imaginings, with the aim of making the idesired things fictional rather than true. ... People who imagine that $P$ are disposed to act in ways that would, if $P$ were fictional, be likely to make the propositions that they i-desire fictional.' [Doggett and Egan 2007: 10] This helps to explain the fact, as we've already noted, that we don't normally act exactly like what we are pretending to be. When pretending to be a dog, one engages in behaviour that more closely matches the conventions for pretenddog behaviour than dog behaviour itself. So perhaps we don't i-desire to fly when we are pretending to be birds because the conventions for pretend-bird behaviour don’t call for it. Birds fly, but pretend (human) birds don't. To make it fictional that I am a bird, Doggett and Egan might claim, I need not fly. Thus, I need not have the i-desire to fly, and this explains why the child constrains herself to an i-desire to flap her wings. But this way of escaping the dilemma seems unsatisfactory. First, it doesn't offer a plausible explanation of why children don't i-desire to fly. It's hard to believe that young children are sufficiently well-schooled in the conventions of pretence to realize that they shouldn't i-desire to fly. Second, the claim seems overly strong. A child need not fly to make it fictional that she is a bird, and thus she need not i-desire that she fly, but that does not support the claim that she should not idesire flying, that it would actually be a mistake for her to do so.
} 
freedom of the imagination but is unable to explain the actual behavior that is produced. Even though children's i-desires are not constrained by real facts, their pretend behavior seems to be. ${ }^{30}$

Given these various problems surrounding the role of i-desires in motivating pretend behavior, we reach a similar conclusion to the one we reached in the context of the problem of conative engagement. Positing i-desires in an attempt to solve the problem of motivation is not just unwarranted but problematic. The actions that we take when we are pretending are best explained in terms of ordinary desires.

\section{Conclusion}

With respect to both the problem of conative engagement and the problem of motivation, we have seen that the proponent of $\mathrm{i}$-desires fails to show that genuine desires are not in play. Moreover, in each of these contexts we have seen that there are positive reasons to avoid introducing i-desires. I-desires do not adequately account for what we are doing either when we engage with fiction or when we take part in pretence. Thus we should reject the i-desire solution to the puzzle of imaginative desire.

Granted, in rejecting this solution, I have not myself offered a comprehensive solution in its place. That said, I take there to be an important positive lesson to be learned from the discussion of this paper. In short, though imaginative desire is puzzling, the puzzle with which we are faced is clearly one about desire.

As we have seen, what lends plausibility to the i-desire solution and thus leads us astray is a reliance on a mistaken and overly restrictive picture of desire. This suggest that the best way to resolve the puzzle of imaginative desire is to get clear on what desire is. Whatever the solution to this puzzle, it will not consist in the invocation of novel mental states. We noted at the start that there are all sorts of connections between imagination and desire. It thus ultimately should come as no surprise that an understanding of what we are doing when we engage with fiction and play games of pretend can come only through a better understanding of genuine desire. ${ }^{31}$

\section{Claremont McKenna College}

\footnotetext{
${ }^{30}$ Moreover, the proponent of i-desires cannot avoid the dilemma by claiming that both i-desires play a role. On this suggestion, we would still face the difficulties of the second horn of the dilemma, namely, why we don't see more attempts at real flying.

${ }^{31}$ Previous versions of this paper were delivered at the 2009 Smartin Workshop on Imagination, Mind, and Morality at Yale University, and the 2009 Pacific Division meeting of the American Society for Aesthetics. I am grateful to the audiences there_-and particularly, to Tyler Doggett and Gregory Currie_-for their insightful comments. Thanks also to my colleagues in the Claremont Colleges Works-in-Progress group and the students in the Pomona College spring 2009 Imagination seminar for their feedback, and especially to Peter Kung for ongoing conversations about this material. This paper has also significantly benefitted from the comments of two anonymous referees for AJP. Finally, I'm grateful as always to Frank Menetrez for his support throughout this project and to Stephen and Joseph for inspiring so many of the examples in this paper.
} 


\section{REFERENCES}

Carruthers, Peter 2006. Why Pretend, in The Architecture of the Imagination, ed. Shaun Nichols, Oxford: Oxford University Press: 89-109.

Currie, Gregory 1995. Imagination and Simulation: Aesthetics Meets Cognitive Science, in Mental Simulation, ed Martin Davies and Tony Stone, Cambridge, Mass.: Blackwell: 151169.

Currie, Gregory 1997. The Paradox of Caring: Fiction and the Philosophy of Mind, in Emotion and the Arts, ed. Mette Hjort and Sue Laver, Oxford: Oxford University Press: 6377.

Currie, Gregory 2002. Desire in Imagination, in Conceivability and Possibility, ed. Tamar Szabo Gendler and John Hawthorne, Oxford: Oxford University Press: 201-221.

Currie, Gregory, and Ian Ravenscroft 2002. Recreative Mind, Oxford: Oxford University Press.

Doggett, Tyler, and Andy Egan 2007. Wanting Things You Don't Want: The Case for an Imaginative Anlogue of Desire, Philosophers' Imprint 7/9: 1-16.

Funkhouser, Eric, and Shannon Spaulding 2009. Imagination and Other Scripts, Philosophical Studies 143/3: 291-314.

Gendler, Tamar Szabo 2000. The Puzzle of Imaginative Resistance, The Journal of Philosophy 97/2: 55-81.

Goldman, Alvin 2006. Simulating Minds: The Philosophy, Psychology, and Neuroscience of Mindreading, Oxford: Oxford University Press.

Gordon, Robert M 1986. Folk Psychology as Simulation, Mind and Language 1/2: 158-171.

Hume, David 1978 (1739). A Treatise of Human Nature, ed. P.H. Nidditch, Oxford: Oxford University Press.

Kind, Amy 2001. Putting the Image Back in Imagination, Philosophy and Phenomenological Research 62/1: 85-110.

Marks, Joel 1984. Motivation and Desire, in Ways of Desire: New Essays in Philosophical Psychology on the Concept of Wanting, Chicago: Precedent Publishing.

Mele, Alfred 1995. Motivation: Essentially Motivation-Constituting Attitudes, The Philosophical Review 104/3: 387-423.

Moran, Richard 1994. The Expression of Feeling in Imagination, The Philosophical Review 103/1: 75-106.

Nichols, Shaun, and Stephen Stich 2003. Mindreading: An Integrated Account of Pretence, Self-Awareness, and Understanding Other Mind, Oxford: Oxford University Press. 
Ryle, Gilbert 1949. The Concept of Mind, Chicago: The University of Chicago Press.

Schroeder, Timothy 2004. Three Faces of Desire, Oxford: Oxford University Press.

Velleman, J. David 2000. On the Aim of Belief, in The Possibility of Practical Reason,. Oxford: Oxford University Press: 244-281.

Walton, Kendall 1990. Mimesis as Make-Believe: On the Foundations of the Representational Arts, Cambridge, Mass.: Harvard University Press.

Walton, Kendall 1997. Spelunking, Simulation, and Slime: On Being Moved by Fiction, in Emotion and the Arts, ed. Mette Hjort and Sue Laver, Oxford: Oxford University Press: 3749.

Weatherson, Brian 2004. Morality, Fiction, and Possibility. Philosophers' Imprint 4/3: 1-27. 